\title{
Peran Penyuluh Pertanian dalam Peningkatan Produktivitas Kelompok Tani di Desa Oesoko Kecamatan Insana Utara
}

\author{
Timotius Titus Tahoni ${ }^{\mathrm{a}}$, Yohanes Pebrian Vianney Mambur ${ }^{\mathrm{b}}$ \\ ${ }^{a}$ Fakultas Pertanian, Universitas Timor, Kefamenanu, TTU - NTT, Indonesia. Email: timotiustahonititus@gmail.com \\ ${ }^{b}$ Fakultas Pertanian, Universitas Timor, Kefamenanu, TTU - NTT, Indonesia. Email: vianneymambur@gmail.com
}

\section{Article Info}

\section{Article history:}

Received 2 Oktober 2020

Received in revised form 10 Oktber 2020

Accepted 25 Oktober 2020

DOI

https://doi.org/10.32938/ag.v5i4.1181

Keywords:

Penyuluh Pertanian

Kinerja

Peranan

\section{Pendahuluan}

Pembangunan pada hakekatnya ialah upaya mencapai taraf hidup rakya yang lebih baik dan sesuia dengan nilai yang berlaku.Petani belajar bukan sekedar mendengar tetapi melihat dan juga melaksanakan dalam kehidupan nyata, karena itulah peran penyuluh pertanian dalam penumbuhan perkembangan kelompok tani bukanlah sekedar jumlah nama kelompok tani.Namun yang terpenting adalah kegiatan kelompok tani sebagai wahana belajar bagi petani dan berkembangnya kelembagaan ekonomi pedesaan yang di awali dengan ciri keswadanyaan dan keswadarsaan petani. Pemberdayaan Kelompok tani dilaksanakan hampir di semua daerah termasuk di Kabupaten Timor Tengah Utara. Kabupaten Timor Tengah Utara memiliki 1.233 Kelompok Tani yang terdiri dari kelas pemula 1.172 Kelompok Tani, kelas Lanjutan 60 Kelompok Tani dan kelas Madya 1 Kelompok Tani yang bergerak dalam luas wilayah Kabupaten Timor Tengah Utara 2669,70 km². (BPS TTU, 2018).

Mardikanto (2017) menjelaskan, penyuluh pertanian merupakan proses perubahan sosial, ekonomi dan politik untuk memberdayakan dan memperkuat kemampuan masyarakat melalui proses belajar bersama yang berpartisipasif, agar terjadi perubahan perilaku pada diri semua stakeholder (individu, kelompok, kelembagaan terkait) yang terlibat dalam proses pembangunan demi terwujudnya kehidupan yang semakin berdaya, mandiri dan partisipasif yang semakin sejahtera secara berkelanjutan. Penyuluh bertugas untuk mendorong, membimbing dan mengarahkan petani/ nelayan agar mampu mandiri dalam mengelola usahataninya karena penyuluh merupakan proses pembelajaran bagi pelaku utama serta pelaku usaha agar mampu menolong dan mengakses informasi pasar, teknologi, permodalandan sumberdaya lainnya sebagai upaya untuk meningkatkan produktivitas, efesiensi usaha, pendapatan dan kesejahteraannya serta meningkatkan kesadaran dalam pelestarian fungsi lingkungan hidup.

Desa Oesoko merupakan salah satu Desa dari 4 Desa lainnya di Kecamatan Insana Utara yang memiliki 7 Kelompok Tani yaitu 2 kelas Lanjut dan 5 kelas Madya. Data Desa Oesoko apabila ditinjau dari penggunaan lahan maka dapat diketahui bahwa lahan sawah (156 ha), lahan kering (92 ha), pekarangan (60 ha). Melihat dari potensi wilayah tersebut maka pembangunan ruang lingkup wilayah yang difokuskan pada peningkatan pendayagunaan lahan sawah dan pekarangan untuk kegiatan pertanian dapat memberikan manfaat dan keuntungan yang sebesar-besarnya bagi masyarakat khususnya petani dan keluarga. Permasalahan yang ada di Desa Oesoko adalah budaya masyarakat yang masih bersifat tradisional yang sulit menerima inovasi baru. Mereka membutuhkan pembuktian untuk melakukan penerapan teknologi anjuran. Sistem pengelolaan alat dan bahan-bahan kelompok tani saat ini tidak ditangani secara benar sehingga menurunnya tingkat produktivitas pertanian dan kelompok tani mengalami kehilangan anggota kelompok.

Produktivitas usaha pertanian yang mereka kelola relatif rendah, hal ini disebabkan tidak digunakannya benih unggul bersertifikat, penggunaan pupuk yang kurang lengkap dan tidak berimbang serta penanganan pasca panen yang kurang tepat. Hal lain yang merupakan permasalahan adalah menurunya tingkat produktifitas lahan yang ditunjukkan dengan sifat fisik tanah yang baik. Penelitian ini bertujuan untuk mengetahui peran penyuluh pertanian dalam peningkatan produktivitas kelompok tani di Desa Oesoko.

\section{Metode}

Penelitian dilaksanakan dari bulan Juli 2020 sampai Agustus 2020 Populasi dalam penelitian ini adalah seluruh Kelompok Tani yang berada di Desa Oesoko yang berjumlah 9 Kelompok Tani. sampel dalam penelitian ini dilakukan dengan cara acak. Sampel dalam penelitian ini berjumlah 45 orang yang terdiri dari 9 Kelompok tani, mengambil 5 orang setiap Kelompok tani menjadi responden.
Metode analisis yang digunakan dalam penelitian adalah metode analisis deskriptif kuantitatif menggunakan skala likert. Metode analisis deskriptif kuantitatif metode ini menghasilkan gambaran akurat tentang sebuah kelompok dan menggambarkan sebuah mekanisme proses atau hubungan.

Analisis regresi linear berganda, hasil kinerja kelompok dapat diukur dari peran penyuluh dibagi dengan kinerja kelompok. Produktivitas kelompok dapat diukur menggunakan rumus sebagai berikut:

$$
Y=a+B 1 X 1+B 2 X 2+B 3 X 3+B 4 X 4+B 5 X 5+e
$$

Dimana:

$\mathrm{Y}=$ Produktivitas kelompok tani

$\mathrm{X}_{1}=$ Inisiator

$\mathrm{X}_{2}=$ Motivator

$\mathrm{X}_{3}=$ Mediator

$\mathrm{X}_{4}=$ Supervisor

$\mathrm{X}_{5}=$ Fasilitator

\section{Hasil Dan Pembahasan}

3.1. Gambaran Pelaksanaan Kegiatan Penyuluhan Pertanian

Interval untuk masing-masing peran penyuluh pertanian dalam meningkatkan produktivitas Kelompok Tani sebagai berikut:

\section{Peran penyuluh pertanian sebagai Inisiator.}

Berdasarkan Tabel 1 menunjukkan bahwa besar jawaban responden adalah kadang-kadang dengan jumlah $20(44.44 \%)$, diikuti responden yang menjawab jarang $10(22.22 \%)$, dan responden yang menjawab sangat sering, sering, dan tidak pernah dengan peresentase yang sama yaitu $5(11.11 \%), 5$ $(11.11 \%), 5(11.11 \%)$. Total skor peranan Inisiator sebesar 130/45 Jiwa $=2.8$ sehingga interprestasi nilainya tergolong Kadang-kadang. Hal ini menunjukkan bahwa peranan penyuluh sebagai Inisiator yang ditunjukan oleh kemampuan memberikan ide-ide baru dengan memanfaatkan sarana-prasarana untuk meraih peluang usaha dan peningkatan pendapatan kelompok, menurut wawancara dengan responden atau petani banyak hal yang kelompok jarang memperoleh informasi dari penyuluh seperti, pengolahan tanah, penanaman, dan pengolahan pupuk. Penelitian ini penyuluh kadang-kadang dalam melakukan kegiatan Inisiator, artinya penelitian ini tidak berbeda jauh dengan penelitian terdahulu dimana jumlah skornya 2.8 dengan kategori kadang-kadang (Miner, 1992).

Tabel 1. Peran penyuluh pertanian sebagai Inisiator

\begin{tabular}{lccc}
\hline \multirow{2}{*}{ Kategori } & \multicolumn{2}{c}{ Jumlah Responden } & \multirow{2}{*}{ Skor } \\
\cline { 2 - 3 } & Jiwa & \% & \\
\hline Sangat Sering (5) & 5 & 11.11 & 25 \\
Sering (4) & 5 & 11.11 & 20 \\
Kadang-kadang (3) & 20 & 44.44 & 60 \\
Jarang (2) & 10 & 22.22 & 20 \\
Tidak Pernah (1) & 5 & 11.11 & 5 \\
\hline Total & 45 & 100 & 130 \\
\hline Rata-rata & & & 2.8
\end{tabular}

Sumber: Data Primer Diolah 2020

2. Peran Penyuluh Sebagai Motivator

Berdasarkan Tabel 2 menunjukkan bahwa besar jawaban responden adalah Kadang-kadang 20 (44.44\%), diikuti responden yang menjawab sering dan jarang dengan peresentase yang sama $10(22.22 \%), 10(22.22 \%)$, dan responden yang menjawab sangat sering $5(11.11 \%)$. Total skor peranan penyuluh sebagai Motivator sebesar $145 / 45$ Jiwa $=3.2$ sehingga interprestasi nilai tergolong jarang. Hal ini menunjukkan bahwa peran penyuluh pertanian 
sebagai Motivator dalam membangkitkan semangat petani agar berpartisipasi dalam kegiatan usahatani kelompok sesuai dengan kriteria. Berdasarkan hasil wawancara dengan anggota kelompok/petani, dalam banyak hal kelompok/petani belum mendapatkan tindakan-tindakan dalam memotivasi antara kelompok dan anggota. artinya penelitian ini tidak berbeda jauh dengan penelitian terdahulu dimana jumlah skornya 3.2 dengan kategori kadang-kadang (Miner, 1992)

Tabel 2. Peran Penyuluh Pertanian Sebagai Motivator

\begin{tabular}{lccc}
\hline \multirow{2}{*}{ Kategori } & \multicolumn{2}{c}{ Jumlah Responden } & \multirow{2}{*}{ Skor } \\
\cline { 2 - 3 } & Jiwa & \% & \\
\hline Sangat sering (5) & 5 & 11.11 & 25 \\
Sering (4) & 10 & 22.22 & 40 \\
Kadang-kadang(3) & 20 & 44.44 & 60 \\
Jarang (2) & 10 & 22.22 & 20 \\
Tidak pernah (1) & 0 & 0 & 0 \\
\hline Total & 45 & 100 & 145 \\
\hline Rata-rata & & \\
Sumber: Data Primer Diolah 2020 & & & 3.2 \\
\hline
\end{tabular}

Sumber: Data Primer Diolah 2020

\section{Peran Penyuluh Pertanian Sebagai Mediator}

Berdasarkan Tabel 3 menunjukkan bahwa besar responden yang menjawab sering dan tidak pernah dengan peresentase yang sama, $15(33.33 \%)$, $15(33.33 \%)$. diikuti yang menjawab kadang-kadang terdapat $5(11.11 \%)$, dan responden yang menjawab tidak pernah terdapat $10(22.22 \%)$. Total skor peran penyuluh sebagai Mediator sebesar $115 / 45$ jiwa $=2.5$ sehingga interperestasi penyuluh tergolong sering dalam memberikan informasi dan mengatasi persoalan yang dihadapi, dalam penelitian ini penyuluh sering memberikan kegiatan Mediator. Penelitian ini berbanding terbalik dimana persentase yang sama dapat dilihat dari skornya yang tertinggi, artinya penelitian ini tidak berbeda jauh dengan penelitian terdahulu dimana jumlah skornya 2.5 dengan kategori sering (Miner, 1992)

Tabel 3. Peran Penyuluh Pertanian Sebagai Mediator

\begin{tabular}{lccc}
\hline \multirow{2}{*}{ Kategori } & \multicolumn{2}{c}{ Jumlah responden } & \multirow{2}{*}{ Skor } \\
\cline { 2 - 3 } & Jiwa & \% & \\
\hline Sangat sering (5) & 0 & 0 & 0 \\
Sering (4) & 15 & 33.33 & 60 \\
Kadang-kadang(3) & 5 & 11.11 & 15 \\
Jarang(2) & 15 & 33.33 & 30 \\
Tidak pernah(1) & 10 & 22.22 & 10 \\
\hline Total & 45 & 100 & 115 \\
\hline Rata-rata & & & 2.5 \\
\hline
\end{tabular}

Sumber: Data Primer Diolah 2020

\section{Peran Penyuluh Pertanian Sebagai Supervisor}

Berdasarkan Tabel 4 besar jawaban responden adalah Jarang 30 (66.66\%), diikuti yang menjawab sering $5(11.11 \%)$, dan responden yang menjawab tidak pernah $10(22.22 \%)$. Total skor peran penyuluh sebagai supervisor sebesar 90/45 Jiwa $=2$ sehingga interprestasi nilai tergolong jarang. Hal ini menunjukkan bahwa peran penyuluh sebagai supervisor yang ditujukkan oleh kemampuan melaksanakan pengawasan dalam mengatasi hambatan kelompok. Berdasarkan hasil penelitian, penyuluh sering melakukan kegiatan supervisor, yang berarti tidak berbeda jauh dengan penelitian terdahulu dimana jumlah skornya 2 dengan kategori sering (Miner, 1992)

Tabel 4. Peran penyuluh Pertanian Sebagai Supervisor

\begin{tabular}{|c|c|c|c|}
\hline \multirow{2}{*}{ Kategori } & \multicolumn{2}{|c|}{ Jumlah responden } & \multirow{2}{*}{ Skor } \\
\hline & Jiwa & $\%$ & \\
\hline Sangat sering (5) & 0 & 0 & 0 \\
\hline Sering (4) & 5 & 11.11 & 20 \\
\hline Kadang-kadang (3) & 0 & 0 & 0 \\
\hline Jarang (2) & 30 & 66.66 & 60 \\
\hline Tidak pernah (1) & 10 & 22.22 & 10 \\
\hline Total & 45 & 100 & 90 \\
\hline Rata-rata & & & 2 \\
\hline
\end{tabular}

Sumber : Data Primer Diolah 2020

5. Peran Penyuluh Pertanian sebagai Fasilitator

Berdasarkan Tabel 5 besar jawaban respon adalah Jarang 20 (44.44\%). Diikuti responden yang menjawab kadang-kadang dan tidak pernah dengan peresentase yang sama $10(22.22 \%), 10(22.22 \%)$, dan responden yang menjawab sering sebanyak $5(11.11 \%)$. Total skor peran penyuluh sebagai Fasilitator sebesar $100 / 45$ Jiwa $=2.2$ sehinga interperestasi nilai tergolong Jarang. Hal ini menunjukan bahwa peran penyuluh sebagai Fasilitator yang ditunjukkan oleh kemampuan melayani kebutuhan-kebutuhan kelompok. Penelitian ini penyuluh Jarang melakukan kegiatan Fasilitator.artinya penelitian ini tidak berbeda jauh dengan penelitian terdahulu dimana jumlah skornya 2.2 dengan kategori jarang (Miner, 1992)

Tabel 5. Peran penyuluh Sebagai Fasilitator

\begin{tabular}{lccc}
\hline \multirow{2}{*}{ Kategori } & \multicolumn{2}{c}{ Jumlah Responden } & \multirow{2}{*}{ Skor } \\
\cline { 2 - 3 } & Jiwa & $\%$ & \\
\hline
\end{tabular}

\begin{tabular}{lccc}
\hline Sangat sering (5) & 0 & 0 & 0 \\
Sering (4) & 5 & 11.11 & 20 \\
Kadang-kadang (3) & 10 & 22.22 & 30 \\
Jarang (2) & 20 & 44.44 & 40 \\
Tidak pernah (1) & 10 & 22.22 & 10 \\
\hline Total & 45 & 100 & 100 \\
\hline Rata-rata & & 2.2 \\
\hline Sumber : Data Primer Diolah 2020 & &
\end{tabular}

6. Skor rata-rata keseluruhan untuk peran penyuluh pertanian dalam meningkatkan produktivitas kelompok sebagai berikut:

Berdasarkan Tabel 6 menunjukkan bahwa skor rata-rata untuk peran penyuluh pertanian terhadap produktivitaas Kelompok Tani yaitu jumlah skor tertinggi adalah peran penyuluh sebagai Motivator dan Inisiator dengan jumlah skor (3.2), (2.8) yang berada pada kategori sering, diikuti peran penyuluh sebagai supervisor dan fasilitator dengan jumlah skor (2), (2.2) yang berada pada kategori Jarang, artinya penyuluh secara teknis dalam melayani kelompok memberikan ide-ide baru dalam pengembangan kinerja kelompok sesuai dengan kriteria yang ada. Skor terendah adalah peran penyuluh sebagai supervisor dengan jumlah skor (2) yang berada pada kategori kadang-kadang.

Tabel 6. Skor rata-rata keseluruhan untuk peran penyuluh dalam meningkatkan produktivitas kelompok

\begin{tabular}{lccc}
\hline Peran penyuluh & Skor rata-rata & Interval kelas & Kategori \\
\hline Inisiator & 2.8 & $3.2-4.1$ & Sering \\
Motivator & 3.2 & $3.2-4.5$ & Sering \\
Mediator & 2.5 & $1.1-4.5$ & Tidak pernah \\
Supervisor & 2 & $2.4-1$ & Jarang \\
Fasilitator & 2.2 & $2.3-1.5$ & Jarang \\
\hline
\end{tabular}

Sumber : Data Primer Diolah 2020

7. Interval untuk keseluruhan peran penyuluh pertanian dalam meningkatkan produktivitas Kelompok Tani

Berdasarkan Tabel 7 menunjukkan bahwa secara keseluruhan peran penyuluh pertanian terhadap produktivitas kelompok berada pada kategori sering dengan jumlah skor rata-rata 2.57 , artinya penyuluh pertanian yang di berikan sering membantu kelompok dalam menjalankan kegiatan kelompok.

Tabel 7. Interval untuk keseluruhan peran penyuluh pertanian dalam meningkatkan produktivitas Kelompok Tani

\begin{tabular}{lccc}
\hline Peran penyuluh & Pertanyaan & Jumlah responden & Total skor \\
\hline Inisiator & 6 & & 130 \\
Motivator & 6 & & 145 \\
Mediator & 6 & & 115 \\
Supervisor & 6 & & 90 \\
Fasilitator & 6 & 45 & 100 \\
\hline Total & 30 & & 580 \\
\hline Rata-rata & & & 2.57
\end{tabular}

Sumber : Data Primer Diolah 2020

\subsection{Analisis Regresi Linear Berganda}

$$
Y=45.289-0.267 X_{1}+0.792 X_{2}-0.75 X_{3}-1.041 X_{4}+1.376 X_{5}
$$

Tabel 8. Hasil SPSS peran penyuluh pertanian di Desa Oesoko

\begin{tabular}{lccc}
\hline Variabel & Koefisien & t-statistik & Prob \\
\hline C & 45.829 & 54.394 & 0,000 \\
X1 (inisiator) & -267 & -4.779 & $0,000^{\mathrm{a}}$ \\
X2 (mediator) & 792 & 10.936 & $0,000^{\mathrm{a}}$ \\
X3 (motivator) & -075 & -2.114 & $0,041^{\mathrm{a}}$ \\
X4 (supervisor) & -1.041 & -10.166 & $0,000^{\mathrm{a}}$ \\
X5 (fasilitator) & 1.376 & 10.874 & $0,000^{\mathrm{a}}$ \\
R-squared & 0.906 & & \\
Prob(F-statistic) & $0,000^{\mathrm{a}}$ & & \\
\hline Keterangan: $a$ signifikan pada $a=0,05$ & &
\end{tabular}

Keterangan: a signifikan pada $a=0,05$

\section{Interprestasi dari model regresi berganda sebagai berikut :}

\section{Inisiator $\left(\mathrm{X}_{1}\right)$}

Inisiator yakni menggali ide-ide baru dan memanfaatkan sarana dan prasarana dalam meraih peluang sehingga membantu petani dalam peningkatan produktivitas berusaha tani. Berdasarkan hasil pengolahan dengan software SPSS16 diperoleh nilai signifikansi variabel Inisiator $0,00<\alpha, 0,05$ maka secara parsial variabel $\mathrm{X}_{1}$ (Inisiator) berpengaruh terhadap kinerja Kelompok Tani (Y). Nilai koefisien regresi Inisiator $\left(\mathrm{X}_{1}\right)$ sebesar -.267 yang artinya setiap penambahan Inisiator dari penyuluh pertanian kepada Kelompok Tani dapat menurunkan kinerja Kelompok Tani. Dimana masyarakat anggota Kelompok Tani dengan bertambahnyainisiator maka akan menambah gagasan yang harus petani terapkan sehingga membuat petani bimbang dalam menentukan gagasan mana yang diprioritas, sehingga meskipun nilai koefisien regresi Inisiator semakin dinaikkan akan tetap mempengaruhinya.penelitian ini tidak berbeda jauh dengan penelitian terdahulu (Van Den Ban, 1992)

2. Motivator $\left(\mathrm{X}_{2}\right)$ 
Motivator yakni berpartisipasi dalam kegiatan usahatani dan pengembangan kinerja Kelompok Tani. Berdasarkan hasil output SPSS 16 diperoleh nilai signifikansi $0,00<\alpha 0,05$ yang berarti secara parsial variabel $\mathrm{X}_{2}$ (Motivator) berpengaruh terhadap kinerja Kelompok (Y) dengan nilai koefesien regresi $\mathrm{X}_{2}$ sebesar 0,792 yang artinya setiap penambahan Motivator akan meningkatkan kinerja kelompok dengan asumsi variabel yang lain tetap. Penelitian ini tidak berbeda jauh dari penelitian terdahulu (Denny,1997)

3. Mediator $\left(\mathrm{X}_{3}\right)$

Mediator yakni membantu memberikan informasi pasar dan membantu anggota dalam menyelesaikan persoalan dalam kelompok. Berdasarkan hasil output SPSS 16 diperoleh nilai signifikansi $0,41>\alpha 0,05$ yang berarti secara parsial $\mathrm{X}_{3}$ (Mediator) tidak berpengaruh terhadap kinerja kelompok (Y) dengan nilai koefisien regresi $\mathrm{X}_{3^{-}} .075$ yang artinya setiap kali penambahan Mediator akan tetap meningkatkan kinerja kelompok. Penelitian ini tidak berbeda jauh dengan penelitian terdahulu

4. Supervisor $\left(\mathrm{X}_{4}\right)$

Supervisor yakni pengawasan dan pengamatan terhadap kegiatan kelompok. Berdasarkan hasil output SPSS diperoleh nilai signifikansi $0,00<\alpha$ 0,05 yang berarti secara parsial variabel $\mathrm{X}_{4}$ (Supervisor) berpengaruh terhadap kinerja kelompok $(\mathrm{Y})$ dengan nilai koefisien regresi $\mathrm{X}_{4}$ sebesar 1.041 yang artinya setiap penambahan Supervisor akan meningkatkan kinerja kelompok dengan asumsi variabel yang lain tetap. Penelitian ini tidak berbeda jauh dengan penelitian terdahulu (Kartasaputra, 1991)

5. Fasilitator $\left(\mathrm{X}_{5}\right)$

Fasilitator yakni melayani kebutuhan-kebutuhan dan memberikan bantuan terhadap kelompok. Berdasarkan output SPSS 16 diperoleh nilai signifikansi $0,00<\alpha 0,05$ yang berarti secara parsial variabel $\mathrm{X}_{5}$ (Fasilitator) berpengaruh terhadap kinerja kelompok $(\mathrm{Y})$ dengan nilai koefisien regresi $\mathrm{X}_{4}$ sebesar 1.376 yang artinya setiap penambahan Fasilitator akan meningkatkan kinerja kelompok.Penelitian ini tidak berbeda jauh dengan penelitian terdahulu (Kartasaputra, 1991)

\section{Analisis Uji Determinasi ( $\left.\mathbf{R}^{2}\right)$}

Dapat dikatakan bahwa dalam model variabel independen (Fasilitator, Mediator, Inisiator, Motivator, Supervisor) secara bersama-sama mampu menjelaskan model regresi sebesar $90.6 \%$ sisanya yaitu sebesar $9.4 \%$ dijelaskan oleh faktor lain yang tidak diuji dalam penelitian.

\section{Analisis Uji Keragaman (Uji F)}

Berdasarkan Tabel 8 Semua variabel bebas secara serentak berpengaruh signifikan terhadap variabel terikat hal ini dapat dilihat dari nilai probabilitas Fstatistik $<0.05$ yang berarti variabel bebas dala hal ini inisiator, mediator, motivator, supervisor dan fasilitator secara serentak berpengaruh signifikan terhadap produktivitas kelompok tani di Desa Oesoko.

\section{Simpulan}

Berdasarkan hasil penelitian peran penyuluh pertanian dalam peningkatan produktivitas Kelompok Tani di Desa Oesoko, maka penulis menyimpulkan bahwa :

Pelaksanaan kegiatan penyuluhan pertanian dalam peningkatan produktivitas Kelompok Tani di Desa Oesoko terdiri dari beberapa indikator yaitu : peran penyuluh sebagai Inisiator, Motivator, Mediator, Supervisor, dan Fasilitator. Hasil penelitian menunjukkan bahwa peran penyuluh pertanian termasuk kategori rendah dengan pencapaian skor meliputi : peran penyuluh sebagai Inisiator (130), Motivator (145), Mediator (115), Supervisor (90), dan Fasilitator (100).

Inisiator, motivator, mediator, supervisor, dan fasilitator berpengaruh signifikan terhadap kinerja kelompok tani Desa Oesoko.

\section{Pustaka}

Badan Pusat Statistik Kabupaten Timor Tengah Utara. 2018. Timor Tengah Utara dalam Angka 2018. Kefamenanu.

Denny, R. 1997. Sukses Memotivasi Kelompok. Jakartta: Balai Pustaka.

Miner. Jhon B. 1992: Kebijakan dan Strategi Manajemen. Jakarta: Erlangga.

Kartasaputra. 1991. Teknologi Penyuluh Pertanian. Jakarta: Bumi Aksara.

Mardikanto. 2007. Peran Penyuluh Pertanian Terhadap Kelompok Tani. Surakarta: University Press.

Van Den Ban. 1999. Penyuluh Pertanian. Yogyakarta; Kanisius. 